\title{
POVOS INDÍGENAS NO BRASIL E AS LIÇÕES DA FLORESTA CULTURAL: A REVOLUÇÃO DA CULTURA DA MANDIOCA NA ECONOMIA DO ATLÂNTICO SUL E NO CONTINENTE AFRICANO
}

\author{
Francisco Alfredo Morais Guimarães ${ }^{1}$
}

\begin{abstract}
Resumo: Neste artigo, é apresentada uma reflexão sobre a pesquisa acadêmica a respeito do saber agrícola dos povos indígenas e o papel de destaque da cultura da mandioca na formação do Brasil e na consolidação do império português, servindo como uma peça de encaixe nas transações mercantilistas no Atlântico Sul. Busca-se evidenciar a visibilidade da mandioca nesse contexto, considerando o reconhecimento da diversidade epistêmica e as especificidades das relações dos povos indígenas no que se refere à natureza e ao arbítrio das construções historiográficas pautadas em uma pretensa universalidade do pensamento europeu, utilizada para legitimar o colonialismo.
\end{abstract}

Palavras-Chave: A mandioca e as lições da floresta cultural. História e cultura indígena no Brasil. Diversidade epistêmica e globalização.

\section{INDIGENOUS PEOPLES IN BRAZIL AND LESSONS OF THE CULTURAL FOREST: THE REVOLUTION OF CASSAVA CULTURE IN THE SOUTH ATLANTIC ECONOMY AND IN THE LIVELIHOOD OF AFRICAN COMMUNITIES}

\begin{abstract}
In this article, a reflection on the academic research on agricultural knowledge of indigenous peoples and the prominent role of cassava in the formation of Brazil and the consolidation of the Portuguese empire, serving as a nipple in mercantilist transactions in the South Atlantic. Aim is to highlight the visibility of cassava in this context, to consider recognizing the epistemic diversity and specificity of the relationship of indigenous peoples with regard to the nature and will of historiographical constructions guided by an alleged universality of European thought, used to legitimize colonialism.

Keywords: Cassava and the lessons of cultural forest.Iindigenous history and culture in Brazil; Epistemic diversity and globalization.
\end{abstract}

A escolha da mandioca como referência para travar uma discussão sobre o saber agrícola dos povos indígenas se deve ao fato de essa planta estar presente na cultura desses povos e de todo o povo brasileiro. Na verdade, constitui-se em uma importante economia de subsis-

1 Doutor em Estudos Étnicos e Africanos pela UFBA, Professor Auxiliar do DEDC/Campus II da Universidade do Estado da Bahia (UNEB). Endereço eletrônico: franciscoguim@gmail.com. 
tência no País, com mais de $85 \%$ da produção da mandioca originada da agricultura familiar, com quase um milhão de trabalhadores do campo se dedicando a seu cultivo. No caso da Bahia, especificamente, o Estado apresenta a maior área de cultivo no País, em torno de 273 mil hectares, com uma produção de 3.367 milhões de toneladas/ano (IBGE, 2013).

Além desses aspectos quantitativos, a cultura da mandioca representa um traço diacrítico cultural e marca da identidade étnica entre povos indígenas, comunidades quilombolas, populações rurais e urbanas em todo o País, apresentando uma considerável importância histórica, econômica e social. Caracteriza, assim, um conjunto de práticas, relações sociais, cosmologias e representações simbólicas, que expressam significados cujos conteúdos revelam o seu grande valor na vida de diferentes segmentos da população brasileira.

\section{RECONHECIMENTO DA MANDIOCA COMO PATRIMÔNIO CULTURAL DO POVO BRASILEIRO}

Figura 1 - Índia do povo Zo'é preparando a farinha de mandioca

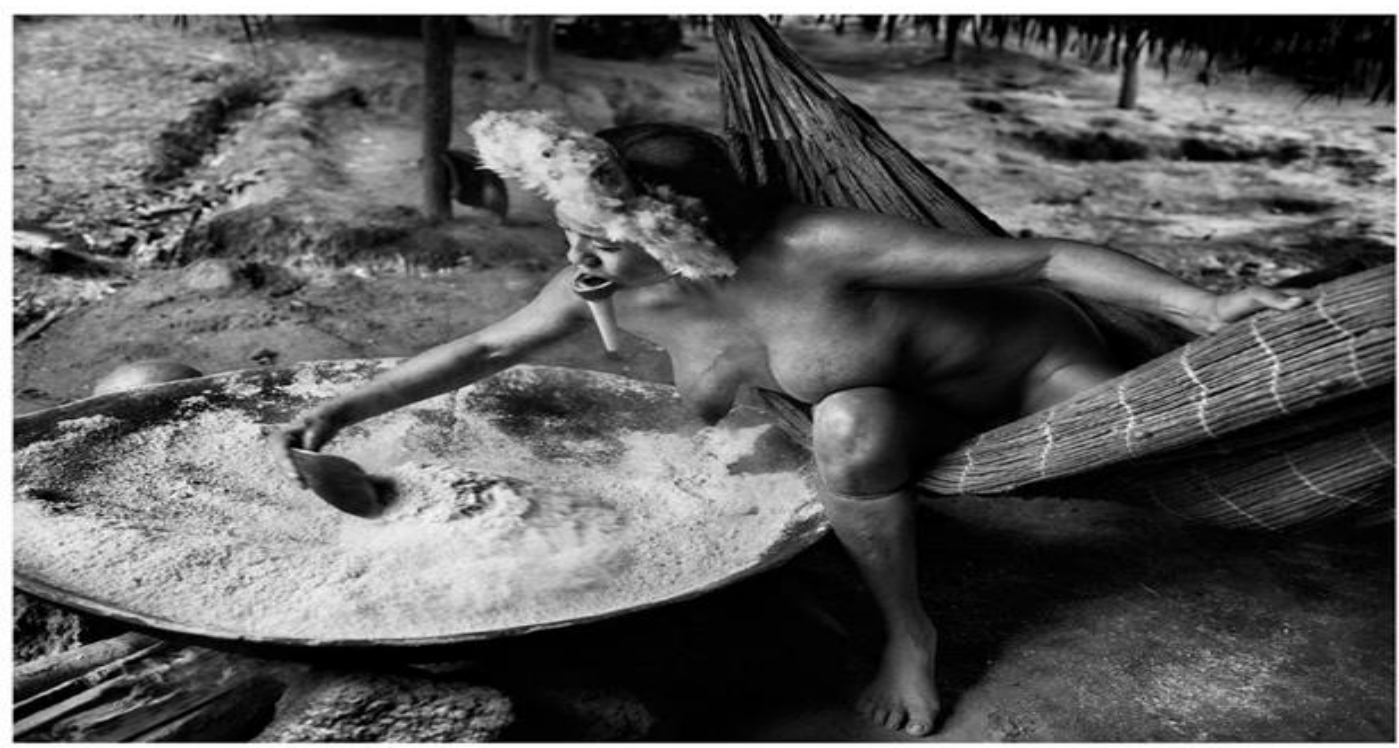

Fonte: Sebastião Salgado (2014) 
Pontos de Interrogação, v. 4, n. 2, jul./dez. 2014

Revista do Programa de Pós-Graduação em Crítica Cultural

Universidade do Estado da Bahia (UNEB), Campus II — Alagoinhas — BA

Levando em conta a perspectiva delineada pela Constituição de 1988, ao reconhecer a dimensão imaterial de parte dos bens culturais no Brasil e, portanto, ampliar o alcance da ação política em relação ao reconhecimento dos elementos que constituem o patrimônio cultural no País, a cultura da mandioca, juntamente com outros bens da cultura popular, passou a contar com a salvaguarda, valorização e proteção como patrimônio imaterial, constando do Registro e Inventário Nacional de Referências Culturais, instituído através do Decreto Federal 3.551, de 4/8/2000, no qual é destacada, no artigo $8^{\circ}$, a criação do Programa Nacional do Patrimônio Imaterial, "visando à implementação de uma política específica de inventário, referente à valorização desse patrimônio" (BRASIL, 2000). Através desse dispositivo, buscou-se instituir uma democratização do poder, reconhecendo a diversidade cultural e legitimando outras maneiras de referenciação identitária, o que representa uma forma de pluralismo constitucional.

Essa perspectiva só foi possível graças a uma visão aplicada ao conceito de cultura, o que permitiu que as visões de mundo, memórias, relações sociais e simbólicas, saberes e práticas fossem tratados enquanto experiências diferenciadas que caracterizam os grupos humanos e se constituem em fundamentos das identidades sociais.

No que diz respeito ao inventário da farinha da mandioca, este foi aberto no Livro dos Ofícios e Modos de Fazer da Mandioca, que reúne um significativo volume de documentos e informações, considerando os modos de fazer os diferentes tipos de farinha e outros produtos e sistemas culinários que envolvem a mandioca. Nele, a diversidade cultural foi contemplada considerando a sua complexidade em saberes, sabores, tecnologias, relações, representações, a sensibilidade e a sociabilidade de diferentes grupos sociais, que a utilizam enquanto agricultores, produtores de uma diversidade de alimentos e como consumidores (VIANNA, 2004).

No Estado da Bahia, por exemplo, existe uma grande diversidade de produtos feitos com a mandioca, além de comunidades que mantêm especificidades em relação à sociabilidade e às representações a respeito dessa planta, como no caso do povo Pataxó, no Extremo-Sul do Estado, onde há uma preferência pelo consumo de um tipo bem específico de farinha, a kwiuna, que é feita a partir da mistura da massa fermentada (puba) com a massa crua da mandioca brava. Essa farinha tem um sabor azedo e sua granulação é bem maior se comparada com outras farinhas produzidas por produtores não índios, como a farinha de copaíba, que é a mais apreciada no Recôncavo baiano e goza de grande prestígio em todo o país. Além disso, os Pataxó fazem o kawin, que é uma bebida de leve teor alcoólico, feita com aipim, água e 
caldo de cana, que é consumida na festa do Awê, um ritual onde ele é distribuído pelos mais velhos. Como afirmam os alunos da Escola Indígena Pataxó Barra Velha, no livro Mãgute e Goyá Pataxó, essa distribuição do kawin é feita "para os adultos e as crianças, para que todos fiquem consagrados com ele" (PROFESSORES Pataxó de Barra Velha, 2007).

\section{A MANDICOCA NO CONTEXTO DA FLORESTA CULTURAL NO BRASIL}

Figura 2 - Roça do povo Suruí na aldeia Sete de Setembro, em Rondônia

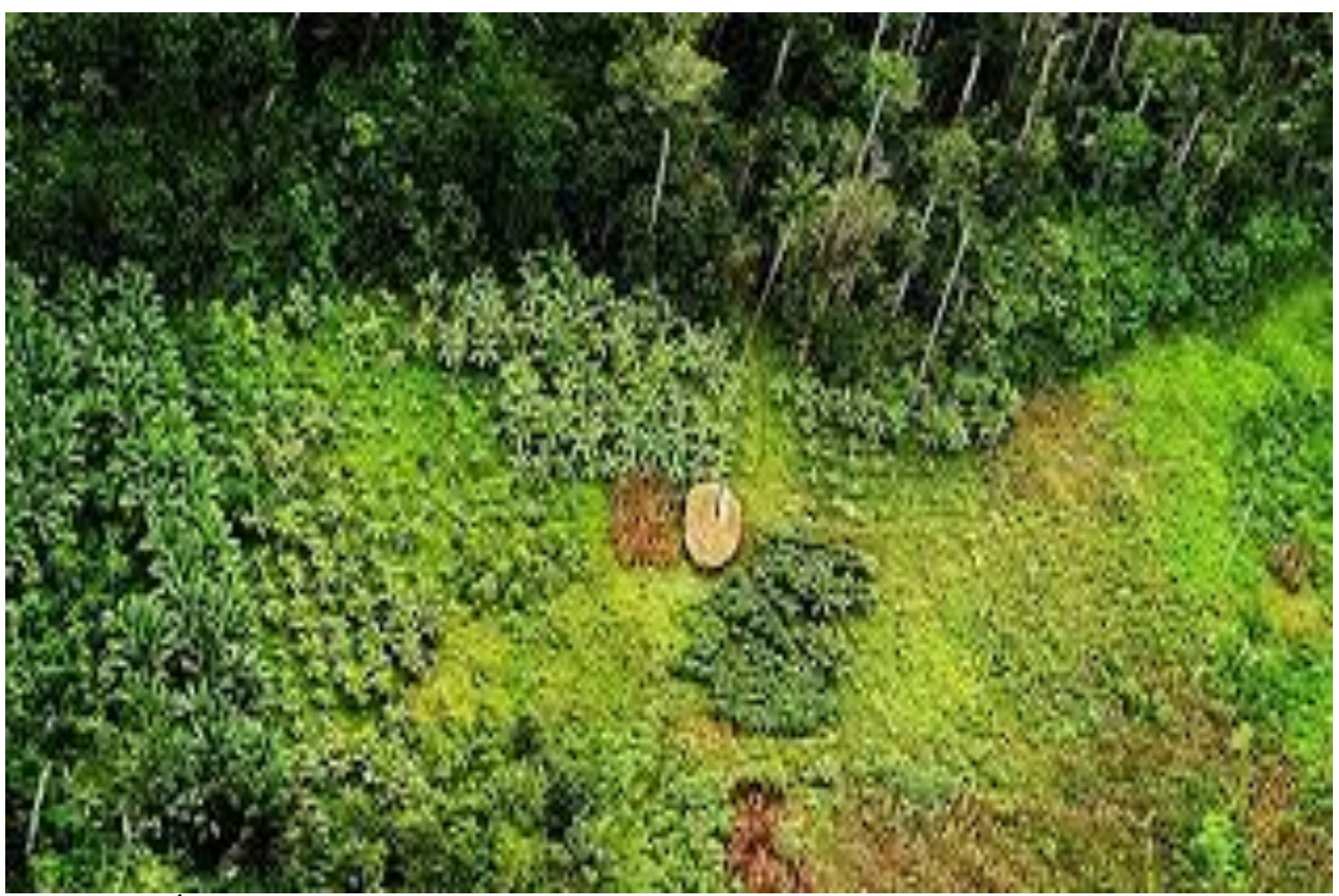

Fonte: Índios de Rondônia (2014)

Entre as características consideradas mais importantes em relação à cultura da mandioca no Brasil, destacam-se a sua longa história de domesticação e a sustentabilidade do seu cultivo, considerando a manutenção por parte dos agricultores, na agricultura familiar, de princípios básicos que estão presentes na agricultura tradicional dos povos indígenas, como a policultura e a rotatividade de solos. Isso tem sido alvo de diversos estudos, sobretudo no campo da ecologia histórica, dando conta da relação dessas práticas com um intenso processo de domesticação e manejo de plantas, fundamentais para o crescimento demográfico e para o sur- 
Pontos de Interrogação, v. 4, n. 2, jul./dez. 2014

Revista do Programa de Pós-Graduação em Crítica Cultural

Universidade do Estado da Bahia (UNEB), Campus II — Alagoinhas — BA

gimento de sociedades complexas, sobretudo na Amazônia brasileira (POSEY, 1986 a/b; BALEÉ, 1989; DESCOLA, 1999; ALBERT; KOPENAWA, 2003).

Tomando como referência a questão da geopolítica do conhecimento, os estudos de ecologia histórica, sobretudo na Região Amazônica, vêm rompendo com o paradigma da naturalização das atividades produtivas dos povos indígenas, configurado desde as primeiras informações apresentadas ao rei de Portugal por Pero Vaz de Caminha, em 1500, quando este apresentou o seu ponto de vista sobre as formas de subsistência do povo aqui encontrado:

Eles não lavram nem criam. Nem há aqui boi ou vaca, cabra, ovelha ou galinha, ou qualquer outro animal que esteja acostumado ao viver do homem. E não comem senão deste inhame, de que aqui há muito, e dessas sementes e frutos que a terra e as árvores de si deitam. (CAMINHA, 1963, p. 9).

Desde essa época, temos, portanto, uma negação da diversidade epistêmica e das constituições históricas e culturais dos povos indígenas e, ao mesmo tempo, a promoção da reificação dessas sociedades. Como assinala Thompson (1990), a reificação se dá por meio da retratação de uma situação transitória e histórica como se fosse permanente, e os processos descritos como coisas, como acontecimentos naturais, ignorando quando foram produzidos e quem os produziu, destituindo-os de historicidade. Conforme o autor, a naturalização é uma estratégia que se estabelece quando um “[...] estado de coisas que representa uma criação social é considerado como um acontecimento natural ou resultado inevitável de características naturais" (THOMPSON, 1990, p. 88).

No caso dos povos indígenas, a reificação dos seus modos de vida se estabelece através da manutenção das relações de poder instituídas desde os primeiros contatos, num contexto caracterizado pela inserção do Brasil nos quadros da economia-mundo capitalista, participando de suas cadeias mercantis e de uma "divisão mundial do trabalho". Conforme Wallerstein (1979), o conceito de divisão mundial do trabalho, caracteriza-se pela presença de um número variado de atividades que demarcam uma "divisão técnica", com a sua ocorrência em diferentes regiões, levando a uma "divisão espacial” e à mobilização de diferentes grupos étnicos para a execução dessas atividades, levando, assim, a uma "divisão étnica" e, por fim, o delineamento de diferentes formas de remunerações, estabelecidas através de uma "divisão de renda".

Assim, conforme o autor, é em função da presença de todos esses elementos na expansão colonial europeia no século XVI que a economia-mundo capitalista pôde criar suas bases 
de sustentação e desenvolvimento, tendo um papel decisivo nesse processo as colônias ibéricas na América (WALLERSTEIN, 1979, p. 142).

Dentro desse contexto, portanto, os povos indígenas deixaram de ser considerados em condição de equivalência de suas capacidades intelectuais e cognitivas, caracterizando, conforme o filósofo inca Aníbal Quijano, uma “colonialidade do poder". Tal perspectiva, segundo ele, foi estabelecida desde os primeiros séculos de dominação europeia, quando foram forjadas as concepções de raça e racismo, que se tornaram o princípio organizador que estruturou e continua a estruturar todas as múltiplas hierarquias do sistema-mundo capitalista (QUIJANO, 1999; QUIJANO, 1993, apud GROSFOGUEL, 2008). Daí, portanto, esse autor afirmar:

\begin{abstract}
Aplicada de maneira específica à experiência histórica latino-americana, a perspectiva eurocêntrica de conhecimento opera como um espelho que distorce o que reflete. Aqui a tragédia é que todos fomos conduzidos, sabendo ou não, querendo ou não, a ver e aceitar aquela imagem como nossa e como pertencente unicamente a nós. [...] Dessa maneira seguimos sendo o que não somos. E como resultado não podemos nunca identificar nossos verdadeiros problemas, muito menos resolvê-los, a não ser de uma maneira parcial e distorcida. [...] Consequentemente, é tempo de aprendermos a nos libertar do espelho eurocêntrico onde nossa imagem é sempre, necessariamente, distorcida. É tempo, enfim, de deixar de ser o que não somos. (QUIJANO, 2005, p. 227-280).
\end{abstract}

Em relação à mudança da visão acadêmica sobre os povos indígenas no Brasil, essa é uma perspectiva que se vem estabelecendo através, por exemplo, da retirada dos sistemas produtivos indígenas da condição de invisibilidade, comprovando que suas atividades tradicionais de subsistência integravam e, em muitos casos, ainda integram, complexos sistemas de produção, alicerçados em minuciosas classificações zoobotânicas e na otimização dos recursos ambientais e na sustentabilidade das intervenções humanas. Essa compreensão tem levado a um delineamento do estatuto da alteridade, lastreado em conceitos como "Sobrenatureza" e "Sobre-humanidade" (VIVEIROS DE CASTRO, 1986). Com esses conceitos, a oposição NaturezalCultura tem-se mostrado insuficiente para acolher metodológica e analiticamente a complexidade das concepções indígenas, revelando o arbítrio das construções historiográficas pautadas em uma pretensa universalidade do pensamento europeu, “[...] como se alguém mostrasse à plateia os fios invisíveis que sustentam os truques do ilusionista" (MICELI, 1991, p. 34).

Seguindo um caminho inverso ao que levou à naturalização das práticas produtivas dos povos indígenas, os novos conceitos formulados na pesquisa etnológica sobre os povos indí- 
Pontos de Interrogação, v. 4, n. 2, jul./dez. 2014

Revista do Programa de Pós-Graduação em Crítica Cultural

Universidade do Estado da Bahia (UNEB), Campus II — Alagoinhas — BA

genas no Brasil apontam para uma ética e uma ecologia simbólica (DESCOLA, 1998), sustentando o princípio da culturalização da natureza, ao demonstrar que, embora sejam invisíveis para um observador desprevenido, as consequências da antropização oriundas dos manejos e práticas agrícolas indígenas estão longe de ser desprezíveis, permitindo que grande parte das florestas em nosso país seja reconhecida como "mata cultural", atribuindo a seus artífices a condição de "selvageria culta" (DESCOLA, 1999, p. 115).

Essa mudança de percurso no estudo da história indígena está relacionada com a revisão de conceitos como "mata virgem", "vazio demográfico" e "estagnação cultural”, utilizados no discurso colonial e na historiografia brasileira com o propósito de justificar o colonialismo, substituindo-os por conceitos como "paisagem humanizada". A partir dessa nova conceituação, as relações específicas das sociedades humanas com a natureza são vistas como uma forma de conhecimento, constituindo-se como o cerne das discussões travadas pelos pesquisadores, ao se considerar a gestão territorial em uma perspectiva histórica.

Um dos exemplos mais significativos da gestão territorial decorrente das práticas de manejo indígenas e que tem sido alvo de uma série de estudos de ecologia histórica na Amazônia, é o sistema agrícola do povo Kayapó, no Pará, assim descrito pela índia Kokoti:

Puru NY (roça nova) é bonita, bem grande, dá trabalho sim, vai ter muito cacau também. Bora plantar nós juntas: jàt, tyrti, môp, kwyre, katenbori, kuni kre! Plantar todo com muita chuva. Aí a roça vai criando, a gente vai tirando batata, inhame, mandioca. Depois na purutum (roça velha), já sabe, tem muita banana e mandioca, daí a gente pega batata e maniva para as outras roças novas. A roça vai ficando velha e depois ibê, ibêny eibêtum (capoeira nova e velha), dá para tirar mamão ainda, tem pidjô (frutas), jenipapo, tem remédio (kane), tem muita caça. Aí vai ficando mata de novo, demora um pouco bà kambrek, bà tyk, dá para fazer roça, derrubar, tocar fogo, plantar, tudo de novo. (KOKOTI KAYAPÓ, apud ROBERT et al., 2012, p. 337).

Em sua fala, Kokoti descreve, de forma processual, como se dá a interação do seu povo com a floresta, onde a coivara, prática agrícola de corte e queima que envolve um complexo sistema de manejo, com uma lógica própria na organização e uso dos recursos naturais, assume uma condição central em um sistema produtivo que se tornou comum entre os povos indígenas e se difundiu junto a outras comunidades tradicionais no Brasil (MUNARI, 2010). 
Pontos de Interrogação, v. 4, n. 2, jul./dez. 2014

Revista do Programa de Pós-Graduação em Crítica Cultural

Universidade do Estado da Bahia (UNEB), Campus II — Alagoinhas — BA

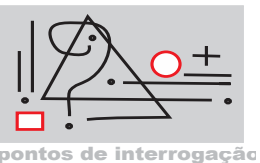

Na sequência de ilustrações apresentadas a seguir, temos uma representação do sistema agroflorestal sucessional biodiverso ${ }^{2}$, que contempla o processo descrito por Kokoti, considerando a existência de 5 etapas, desenvolvidas num período de 40 anos.

Figuras 3, 4, 5, 6 e 7 - Sistema Agroflorestal Sucessional Biodiverso.

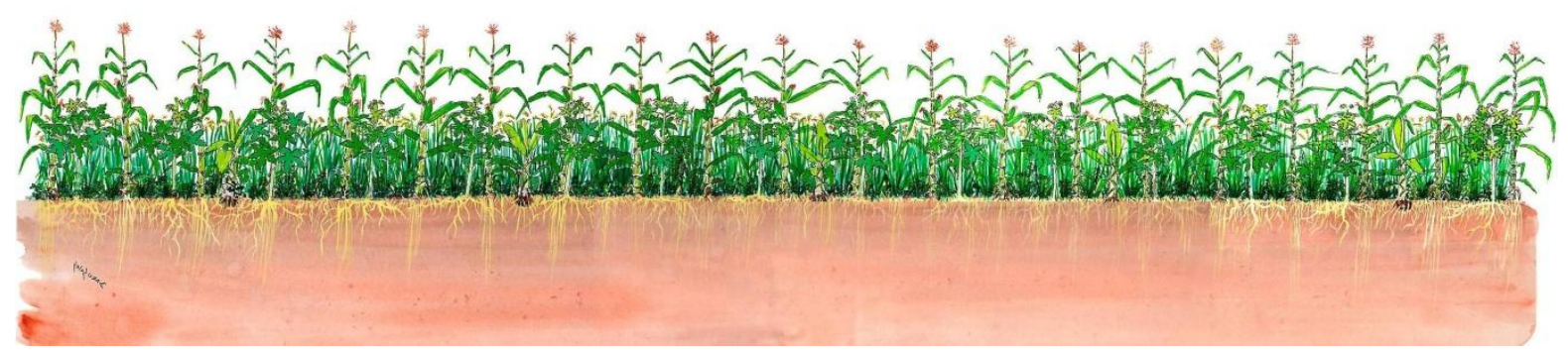

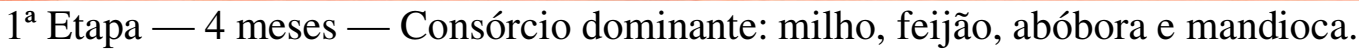

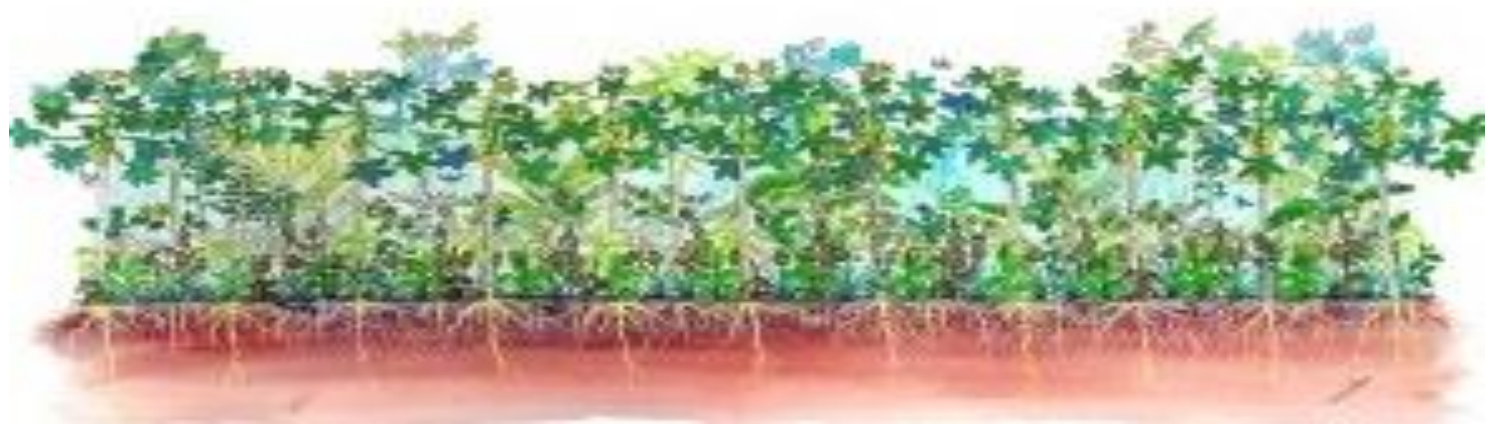

$2^{\mathrm{a}}$ Etapa - Consórcio dominante: balsa, embaúba, mamão, banana da prata e abacaxi.

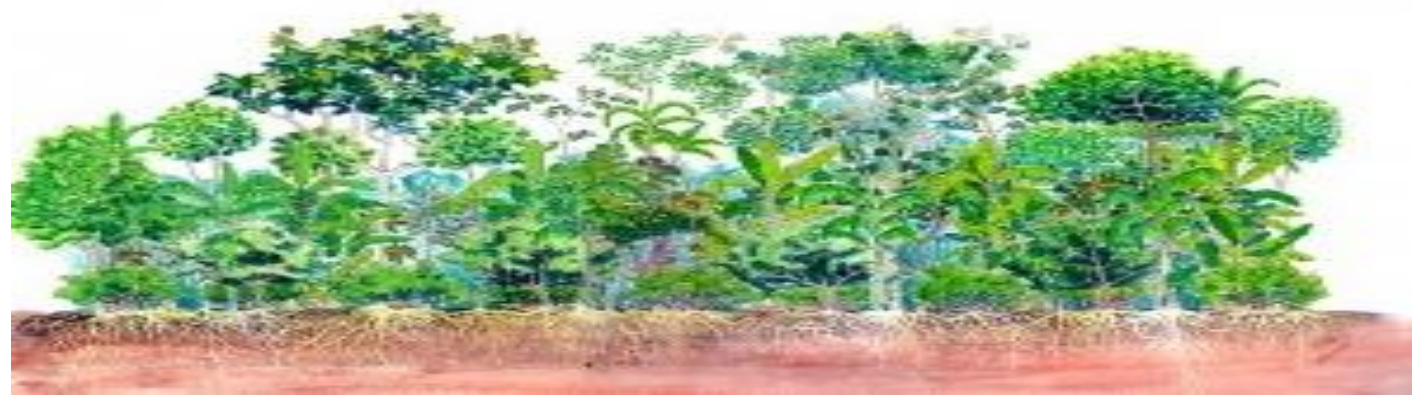

$3^{\mathrm{a}}$ etapa -5 anos - Consórcio dominante: balsa, pupunha, banana e urucum.

2 Essas ilustrações integram uma animação feita por pesquisadores da Universidade Federal do Acre, através do projeto arboretolparque zoobotânico e que está disponível no site <http://media0.agrofloresta. net/static/mochila_do_educador_agroflorestal/animacao.htm>. 


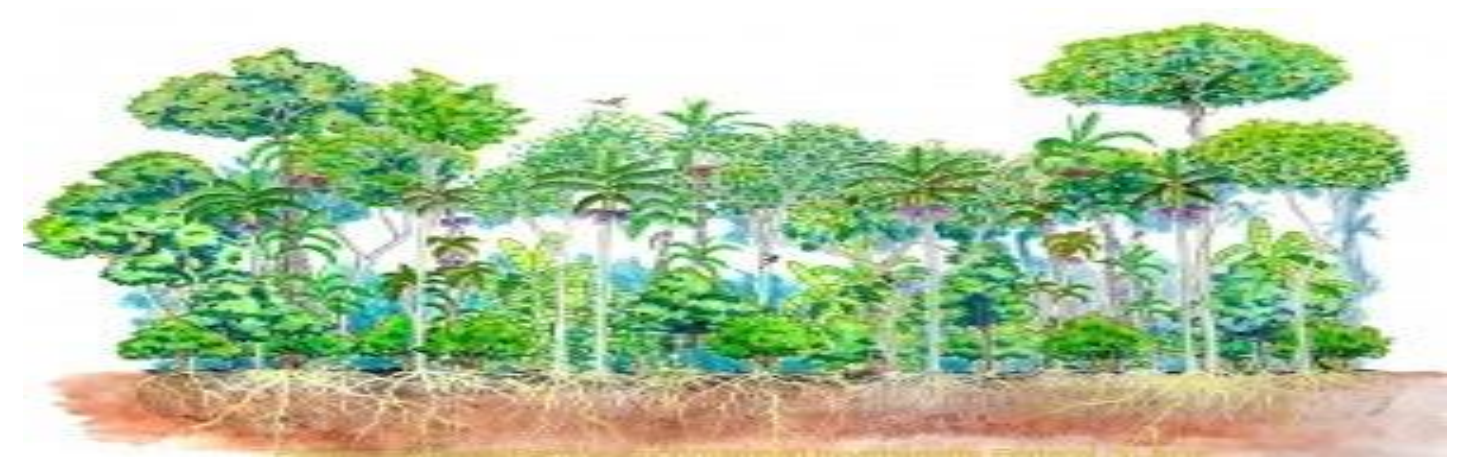

$4^{\mathrm{a}}$ etapa - 18 anos - Consórcio dominante: sumaúma, castanheira do Pará, seringuei-

ra, pupunha, açaí, banana, cupuaçu e cacau.

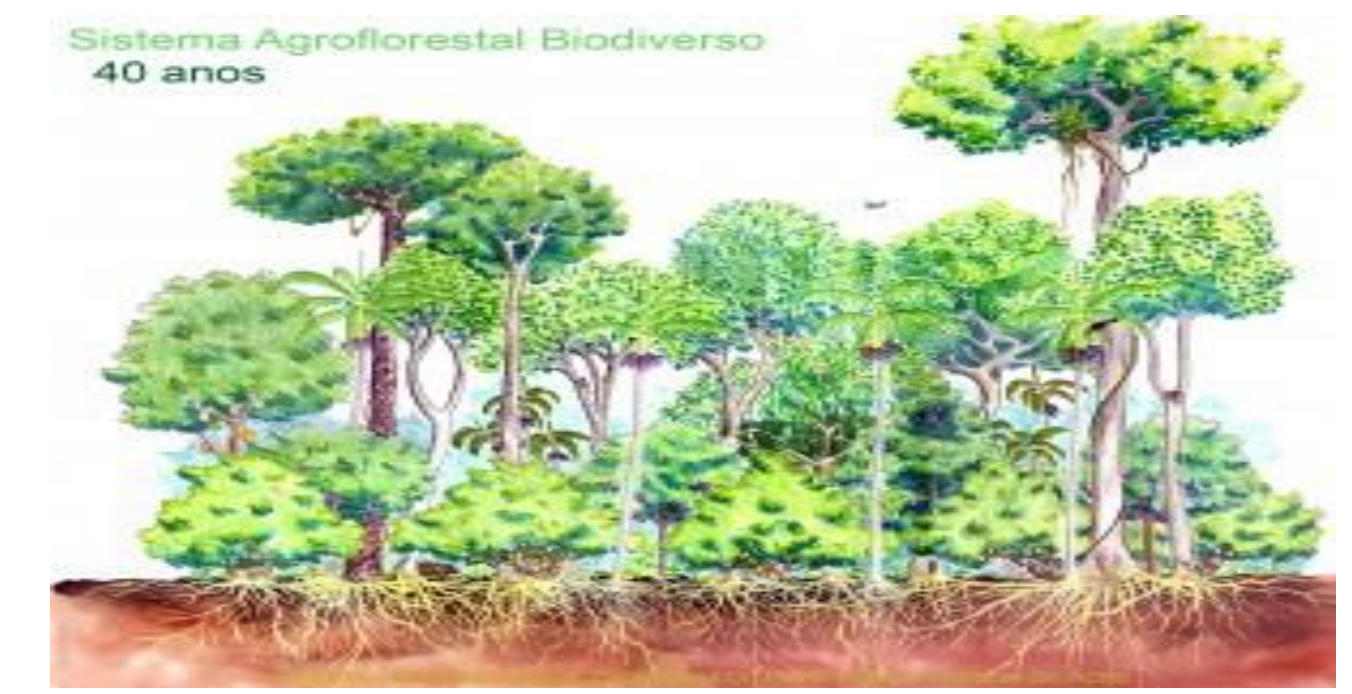

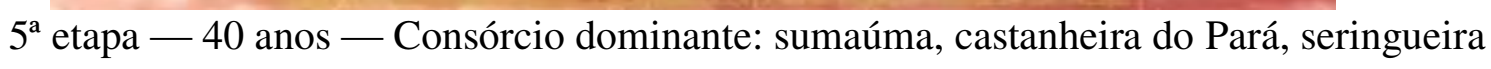
e cacau.

Fonte: SISTEMA Agroflorestal... (2010).

Com os estudos sobre os sistemas produtivos indígenas, temos a efetivação do que Santos (2007) caracteriza como um "pensamento pós-abissal", ou seja, um pensamento que se estabelece como "um aprender com o Sul usando uma epistemologia do Sul". Essa nova dimensão do pensamento, segundo ele, caracteriza uma ecologia de saberes, por ser baseada na “ideia de que o conhecimento é interconhecimento", ou seja, ele se estabelece através de uma “copresença radical”, onde, em ambos os lados da linha, há um reconhecimento em termos igualitários e contemporâneos das práticas e dos agentes. Mas um reconhecimento que, segundo o autor, "[...] implica conceber simultaneidade como contemporaneidade, o que só pode ser conseguido abandonando a concepção linear de tempo" (SANTOS, 2007, p. 24). 
Nesse "aprender com o Sul", onde as "lições da floresta cultural" apresentam diferentes perspectivas de estudo, a mandioca tem assumido uma condição de destaque, considerando a antiguidade de sua domesticação, aproximadamente sete mil anos, e a engenhosidade dos agricultores indígenas no sentido de desenvolver variedades da planta com baixa concentração de cianeto de hidrogênio, que é uma substância extremamente tóxica, bem como a descoberta de modos eficientes para sua extração e a conservação da mandioca em forma de farinha, o que possibilitou a subsistência das comunidades indígenas mesmo em períodos de escassez.

\section{O PAPEL DA CULTURA DA MANDIOCA NA FORMAÇÃO DO BRASIL E NA CONSOLIDAÇÃO DO IMPÉRIO PORTUGUÊS}

Figura 8 - Casa de Farinha de Mandioca.

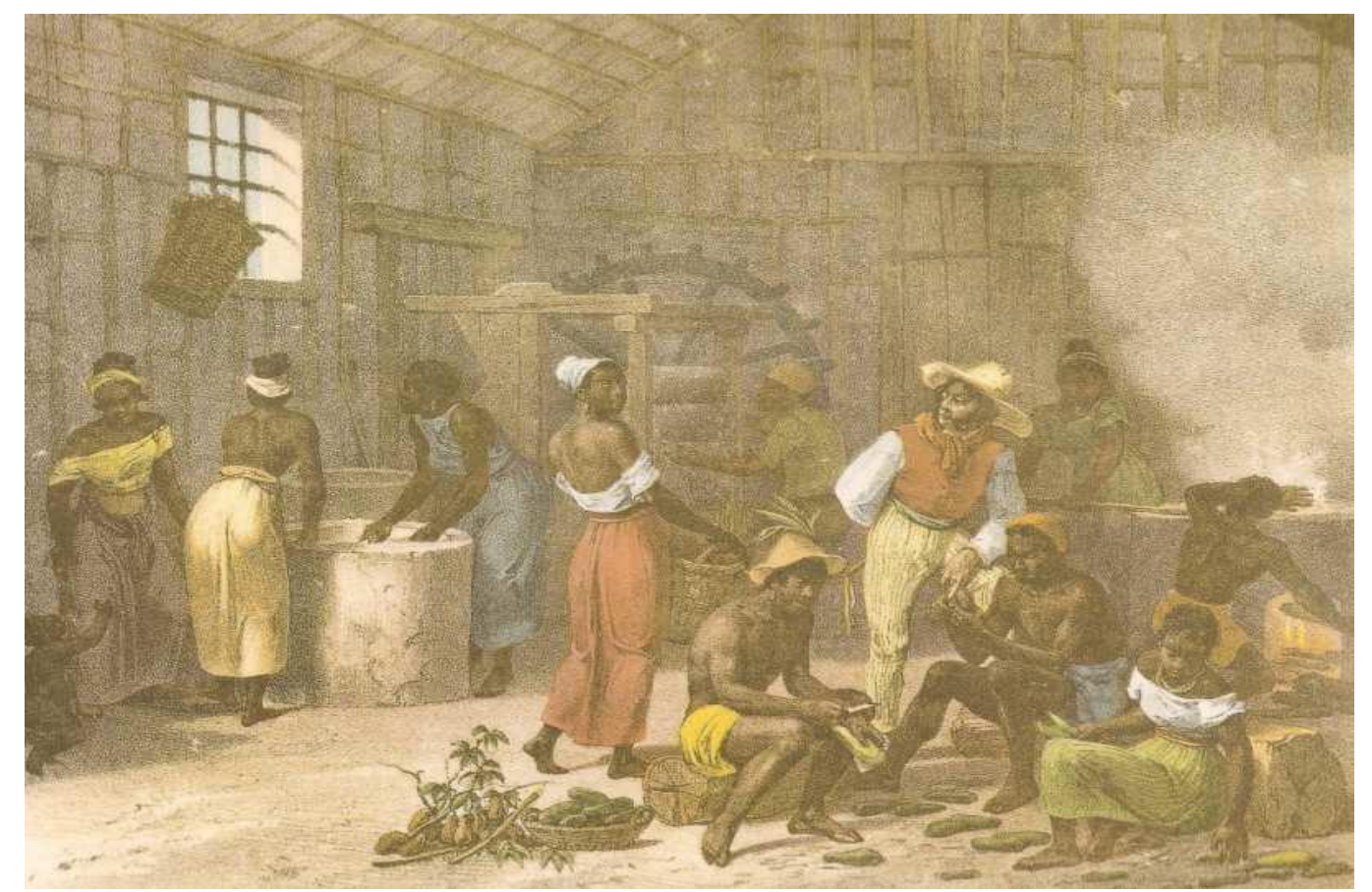

Fonte: Rugendas (1835).

Todos esses elementos, somados às vantagens do cultivo da mandioca, como o elevado volume de carboidrato por área e durante muitos meses por ano, mesmo em situações difíceis e até adversas de solo e clima (baixa fertilidade, baixo nível de matéria orgânica, muita areia, estiagens, etc.), capacidade de regeneração e de adaptação ecológica, reprodução vegetativa, possibilidade de cultivo consorciado com outras culturas, juntamente com a possibilidade de 
Pontos de Interrogação, v. 4, n. 2, jul./dez. 2014

Revista do Programa de Pós-Graduação em Crítica Cultural

Universidade do Estado da Bahia (UNEB), Campus II — Alagoinhas — BA

ser mantida no solo durante um longo período (até dois anos) e colhida quando necessário, levaram a sua difusão junto aos núcleos coloniais no Brasil. Como informa Ambrósio Fernandes Brandão, no livro Diálogos das Grandezas do Brasil, escrito no início do século XVII:

[...] os mantimentos, de que se sustentam os moradores do Brasil, brancos, índios e escravos de Guiné, são diversos, uns sumamente bons, e outros não tanto; dos quais os principais e melhores são três, e destes ocupa o primeiro lugar a mandioca, que é a raiz de um pau, que se planta de estaca, o qual, em tempo de um ano, está em perfeição de se poder comer, e, por este mantimento se fazer de raiz de pau, lhe chamam em Portugal farinha de pau. (BRANDÃO, 1930, p. 164).

Mas a propriedade da mandioca que mais chamou a atenção dos portugueses foi a conservação da sua farinha por meses a fio, o que fazia com que os índios a chamassem de farinha de guerra. Como informa Gabriel Soares de Sousa, no seu Tratado Descritivo do Brasil, escrito em 1587:

[...] farinha-de-guerra se diz, porque o gentio do Brasil costuma chamar-lhe assim pela sua língua, porque quando determinam de ir fazer a seus contrários algumas jornadas fora de sua casa, se provem desta farinha, que levam às costas ensacada em uns fardos de folhas que para isso fazem, da feição de uns de couro, em que da Índia trazem especiaria e arroz; mas são muito mais pequenos, onde levam esta farinha muito calcada e enfolhada, de maneira que, ainda que the caia num rio, e que lhe chova em cima, não se molha. (SOUSA, 1971, p. 194).

Como os portugueses não dispunham de nenhum alimento tão nutritivo quanto a farinha de mandioca que pudesse ser conservado por tanto tempo, logo eles se deram conta das vantagens da sua introdução na dieta dos marinheiros que faziam as viagens transatlânticas, o que provocou uma verdadeira revolução, devido à grande redução na taxa de mortalidade dos marinheiros, mas, sobretudo, dos escravos transportados nos navios negreiros, o que permitiu uma maior lucratividade para os traficantes. Com isso, é possível afirmar que, sem se apoiarem nas lições do saber agrícola dos povos indígenas, os portugueses teriam o seu projeto colonial e imperial inviabilizado, considerando que a farinha de mandioca passou a ser a fonte alimentar de carboidratos nas suas mais importantes investidas na conquista do Brasil e em suas transações econômicas no Atlântico Sul.

Referindo-se a essa questão, Alencastro (2000) assinala que, a partir do século XVII, a farinha de mandioca passou a ser uma das peças de encaixe na economia do Atlântico Sul, constituindo-se não só como o alimento principal das tripulações dos tumbeiros, mas também dos escravos à espera de embarque nos portos africanos e das tropas envolvidas com o comércio de escravos, a exemplo das guerras brasílicas em Angola (ALENCASTRO, 2000). Nesse 
Pontos de Interrogação, v. 4, n. 2, jul./dez. 2014

Revista do Programa de Pós-Graduação em Crítica Cultural

Universidade do Estado da Bahia (UNEB), Campus II — Alagoinhas — BA

sentido, o autor aponta para a introdução da cultura da mandioca nas regiões tropicais da África a partir de um processo que, segundo ele, obedeceu a três etapas:

Num primeiro momento, a América exporta mandioca através da Guanabara e do litoral vicentino. Numa segunda etapa, a mandioca, o milho, a batata-doce e frutas sul-americanas passam a ser plantados nas terras africanas. No preparo da farinha de mandioca africana vigorava o método brasílico. [...]. Num terceiro tempo, tais culturas espalharam-se pelos sertões africanos [...]. (ALENCASTRO, 2000, p. 254).

Tomando com referência as argumentações de Wallerstein (1979), Soares (2008) assinala que a introdução do comércio e da produção da farinha de mandioca na economia do Atlântico Sul teve uma relação direta com a própria necessidade de expansão mercantilista portuguesa entre o Atlântico e o Oriente, num contexto marcado pela hierarquia entre os homens e entre produtos, definida pela divisão mundial do trabalho. Essa divisão articulou-se a variadas e extensas redes de produção e troca, com a mandioca passando a ocupar um lugar importante no consumo da população do ultramar (SOARES, 2008; 2009).

Esse reconhecimento da mandioca como uma "peça de encaixe na economia do Atlântico Sul" se contrapõe ao desprestígio dados a ela na historiografia brasileira, onde o foco, até bem pouco tempo, esteve direcionado para outras atividades produtivas, sem se levar em conta a questão da subsistência dos diversos sujeitos sociais integrados à economia-mundo no Brasil e em todo o império português.

Chamando a atenção para uma necessidade de revisão na historiografia em relação ao estudo do tráfico de escravos procedentes de Angola, Alencastro (2000) defende a tese da existência de um "ciclo da mandioca" na economia colonial brasileira, entre os anos de 15901630, considerando uma série de práticas comerciais, como aquelas realizadas pelos padres Jesuítas da Bahia, que

[...] exportavam mandioca para os missionários de Angola em troca de escravos. [...] Afora o sustento dos militares e dos padres, o transporte e a guarda - durante meses - de centenas de cativos em trânsito induziam à armazenagem de gêneros alimentícios junto às feiras e portos de trato africanos. [...] Ao lado da batata-doce e do milho [...], a farinha de mandioca servia de sustento aos cativos, aos soldados e ao tráfico terrestre, fluvial e marítimo de escravos da conquista. (ALENCASTRO, 2000, p. 91-94).

Levando em conta essa difusão e a democratização da cultura da mandioca na África, Sacramento (2011) ressalta que,

[...] embora tenha percorrido um caminho vagaroso, em seu processo de difusão e transformação, a mandioca se impôs entre os tubérculos mais cultivados e consumidos no continente africano rom- 
Pontos de Interrogação, v. 4, n. 2, jul./dez. 2014

Revista do Programa de Pós-Graduação em Crítica Cultural

Universidade do Estado da Bahia (UNEB), Campus II — Alagoinhas — BA

pendo fronteiras de classe. É nesse sentido que a atual República do Benin tem construído uma política de fortalecimento do agronegócio elegendo a mandioca como uma das principais produções agrícolas, depois do inhame. Trata-se, não por acaso, de um reconhecimento das potencialidades econômicas desse produto no mercado, seja pela plêiade de derivados, pela sua inserção em diversos ramos industriais (de alimentos embutidos, embalagens, colas, mineração, têxtil e farmacêutico) ou sua importância na segurança alimentar e nacional de vários países dos continentes africano e americano. (SACRAMENTO, 2011, p. 5).

Figura 9 - Preparo de beiju de mandioca na Nigéria

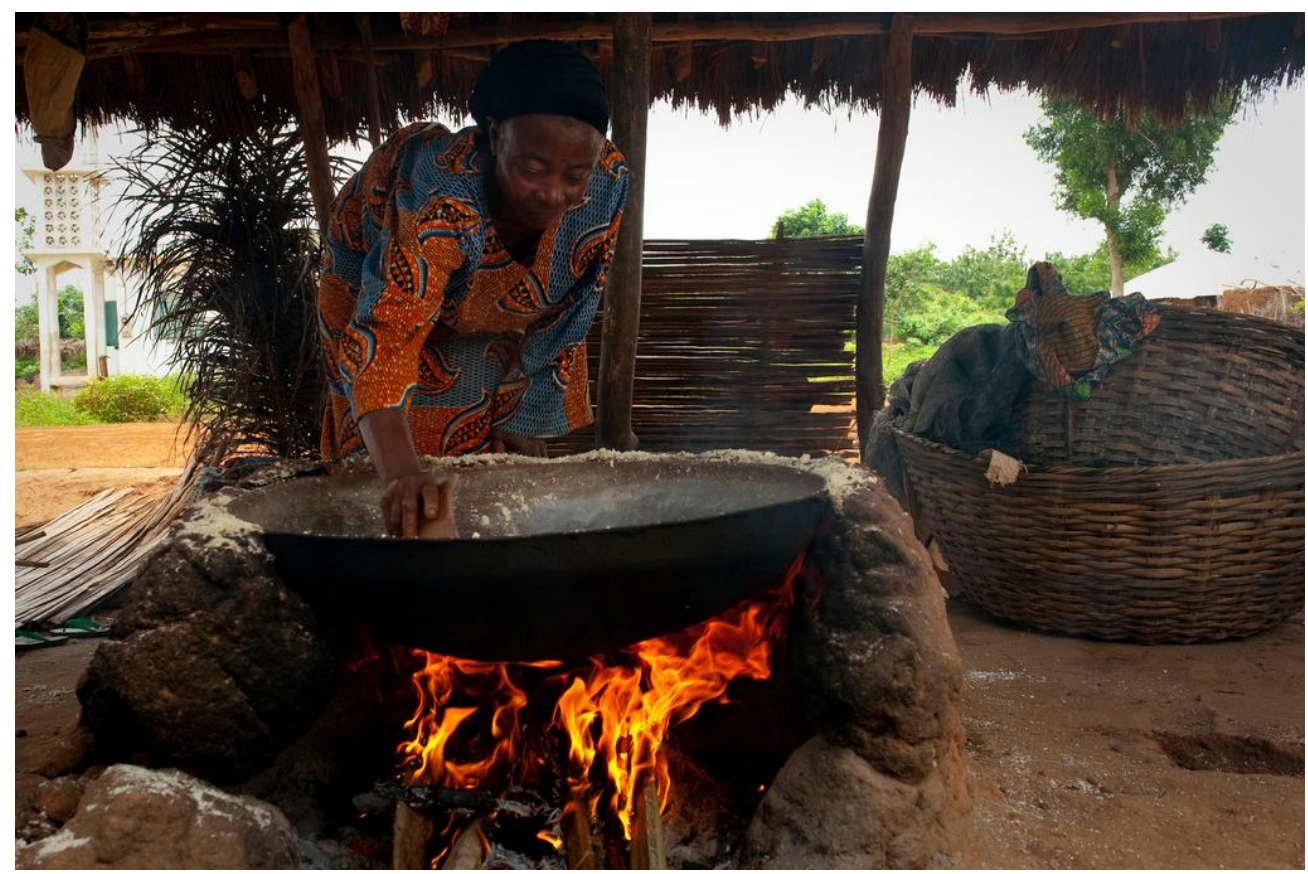

Fonte: World Foods - Cassava (2014).

Hoje, é possível constatar o resultado desse processo, considerando a grande difusão da mandioca pelo mundo, tendo uma grande importância na segurança alimentar, de modo especial para os agricultores de subsistência e comunidades carentes na África. No continente africano é onde se concentra a maior produção mundial, com a Nigéria sendo o primeiro produtor mundial, produzindo, em 2011, mais de 53 milhões de toneladas, mais que o dobro do segundo produtor mundial, que é o Brasil, com aproximadamente 25 milhões de toneladas (FAO, 2013 a).

Conforme destaca a FAO, órgão da ONU, a mandioca é o "alimento dos pobres" e tornou-se uma cultura polivalente que responde às prioridades dos países em desenvolvimento, às tendências da economia global e ao desafio da mudança climática. Além disso, em função da contribuição dada pelas populações tradicionais à conservação, melhoria e disponibilidade dos recursos fitogenéticos, $a$ FAO (2013 b) reconhece os seus direitos à remuneração dessa 
Pontos de Interrogação, v. 4, n. 2, jul./dez. 2014

Revista do Programa de Pós-Graduação em Crítica Cultural

Universidade do Estado da Bahia (UNEB), Campus II — Alagoinhas — BA

contribuição e estabeleceu um Fundo Internacional para os recursos fitogenéticos, para efetivar esse propósito. [Confira a informação FAO, 2013 b]

\section{CONCLUSÃO}

Considerando o que os estudos de ecologia histórica vêm revelando sobre o conhecimento agroecológico dos povos indígenas no Brasil, bem como o reconhecimento pelos historiadores do papel da cultura da mandioca enquanto uma peça de encaixe na economia do Atlântico Sul, fica patente a importância de uma reflexão sobre essa temática no âmbito escolar, visando o seu tratamento de forma interdisciplinar no ensino da história e cultura de povos indígenas no Brasil, implementando, assim, as prerrogativas da Lei Federal 11.645/2008 (BRASIL, 2008).

No que diz respeito ao ensino de história, especificamente, esse tema pode ser contemplado considerando que historiadores e autores dos livros didáticos da matéria, embasados em referenciais teóricos anacrônicos, como o evolucionismo cultural, apresentam uma visão didática sobre o índio, caracterizada pela subalternidade, estagnação e inferioridade cultural e destituindo os povos indígenas de uma condição de equivalência de suas capacidades intelectuais e cognitivas. Foi justamente dentro desse enquadramento que se configurou a naturalização da violação dos direitos indígenas, dando mostras, como observa Santos (2004, p. 76), de que “[...] a injustiça social contém no seu âmago uma injustiça cognitiva”.

Essa é uma perspectiva que está em consonância com o posicionamento de professores e lideranças indígenas em todo o país, que destacam os problemas por eles identificados em relação ao tratamento da temática indígena na escola, ao questionar, por exemplo, a permanência do termo "descobrimento" no ensino de História do Brasil. Conforme o professor indígena Onalvo Jesus dos Santos, da etnia Kiriri, na Bahia,

[...] o termo descobrimento foi utilizado pelos colonizadores, que vieram com outra visão e começaram a explorar as riquezas que encontraram aqui e começaram a transformar e também começaram a dizimar, a escravizar os próprios nativos que existiam também.

Aí, muitas coisas foram transformadas. Trouxeram uma língua diferente para colonizar, pra dominar. E hoje é uma luta muito longa dos povos indígenas no Brasil pra contra vencer esse tipo de imagem que é muito forte. Porque o dominante estava lá, estava com suas leis. Estava lá no palácio dele lá e mandando as leis para os povos indígenas acompanhar a mesma cultura.

[...] É isso que a gente que faz parte do movimento indígena percebe. É muito forte a gente contravencer essa palavra descobrimento. Os historiadores são os mais a defenderem essa palavra desco- 
brimento, porque se eles não defendessem, com certeza já tinham mudado a palavra descobrimento.

[...] Eu vejo que a educação é que pode transformar tudo isso aí. A educação. É através das universidades, é através de um estudo mais aprofundado sobre a história do Brasil dentro das instituições, para que leve dentro do pensamento dos próprios mestres que estão aí dentro, dos próprios acadêmicos ali, essa visão. Não uma visão preconceituosa como a gente está vendo aí, essa visão bem baixa, vamos dizer assim de centésima categoria dos povos indígenas. (SANTOS, apud GUIMARÃES, 2014, p. 191).

$\mathrm{Na}$ fala do professor Onalvo, que também é uma liderança do povo Kiriri, fica evidente a sua posição crítica em relação ao uso do termo "descobrimento", contextualizando-o a partir do seu olhar enquanto professor e ativista indígena, em oposição a seu uso pelos colonizadores e a sua defesa pelos historiadores.

De forma crítica e propositiva, o professor formula o conceito "contra vencer", que define o protagonismo indígena e o poder transformador da educação, reconhecendo nela uma possibilidade de intervir na realidade, demonstrando a indissociação entre a educação e o projeto social e político dos povos indígenas e o processo de politização que deve ser vivenciado na universidade pelos mestres e acadêmicos, com vistas a uma mudança da visão preconceituosa em relação aos povos indígenas.

Além disso, através de sua crítica aos historiadores, o professor Onalvo revela um aspecto ocultado nos Livros Didáticos Nacionais de História, que é a presença de uma versão historiográfica respaldada nas epistemologias dominantes. Sendo assim, dentro dos parâmetros delineados por Santos (2009, p. 32-45), o discurso do professor pode ser visto como uma "heresia epistemológica", ou uma "contra-epistemologia", ao evidenciar, na luta dos povos indígenas, a necessidade de contra vencer a imagem de um "exclusivismo epistemológico" colonial, caracterizado pela prevalência de outra língua e de leis que os mantiveram dentro de uma condição de subalternidade perante o Estado nacional brasileiro.

Essa condição de subalternidade é evidenciada pelo professor, ao ressaltar a recusa a se reconhecer os povos indígenas como nações, o que, conforme Little (2002, p. 6), caracteriza uma dificuldade que o próprio Estado teve e tem em reconhecer a existência de outros territórios dentro do Estado-nação, por representar "[...] um desafio para a ideologia territorial do Estado, particularmente para sua noção de soberania".

A fala do professor Onalvo caracteriza um fenômeno de autoria indígena, que, como assinala César (2002), se estabelece quando sujeitos individuais ou coletivos, através de práticas 
e atos sociais e discursivos diversos, estabelecem o deslocamento de posições hegemonicamente construídas e, dessa forma, “[...] potencializam a capacidade de articulação discursiva — que é antes de tudo política — e se ‘autorizam' como 'produtores de discursos"' (CÉSAR, 2002, p. 76 ).

Assim, é possível contextualizar o posicionamento do professor Onalvo, reconhecendo nele uma correspondência com as transformações no campo político ocorridas no Brasil, com o intenso processo de mobilização popular que resultou no estabelecimento da Constituição, em 1988, que entre outras conquistas, apresenta uma configuração política pluriétnica. Na nova Carta Magna, em face das reivindicações e lutas dos povos indígenas, se estabeleceu um redirecionamento na orientação ideológica do Estado, imprimindo novos conceitos e novas práticas em relação à política indigenista, na qual o princípio do pluralismo jurídico está expressos em oito dispositivos isolados, em um capítulo no título "Da Ordem Social" e em um artigo que consta do Ato das Disposições Constitucionais Transitórias, nos quais se dá o reconhecimento do direito a organização social, costumes, línguas, crenças e tradições dos povos indígenas, bem como o direito originário sobre as terras que tradicionalmente ocupam. (BRASIL, 1988).

Cabe, contudo, salientar que apesar dos avanços em relação ao pluralismo jurídico no Brasil, há muitas limitações na positivação de instrumentos para sua sustentação e no estabelecimento de condições para sua plena efetividade, pondo em prática o estímulo a validade das normas e das decisões indígenas, face ao seu confronto com diversos interesses econômicos que, como destacado anteriormente, estão relacionados a própria inserção do país nos quadros da economia-mundo capitalista, e as pressões sobre as terras indígenas. Essa situação, como assinala Santos (2008), caracteriza "um atraso chocante do país em relação ao que se passa no continente. $O$ índio ainda não tem uma plena capacidade jurídica. Reconhecem-se as suas terras, mas não se reconhece o seu direito para as administrar” (SANTOS, 2008, p. 39).

\section{REFERÊNCIAS}

ALBERT, Bruce; KOPENAWA, Davi. Yanomami, l'esprit de la forêt. Paris: Fondation Cartier pour l'Art Contemporain ; Arles: Editions Actes Sud, 2003.

ALENCASTRO, Luiz Felipe de. O Trato dos Viventes: formação do Brasil no Atlântico do Sul, séculos XVI e XVII. São Paulo: Companhia das Letras, 2000. 
AMOS, Alcione Meira. Os que voltaram: a história dos retornados afro-brasileiros na África Ocidental no século XIX. Belo Horizonte: Tradição Planalto, 2007.

BALÉE, William. Cultura na vegetação da Amazônia brasileira. In: NEVES, Walter Alves (Org.). Biologia e ecologia humana na Amazônia: avaliação e perspectivas. Belém: Museu Paraense Emílio Goeldi, 1989. p. 95-109 (Coleção Eduardo Galvão).

BEZERRA, Nielson Rosa. Escravidão, farinha e tráfico atlântico: um novo olhar sobre as relações entre o Rio de Janeiro e Benguela (1790-1830). Rio de Janeiro: Fundação Biblioteca Nacional, 2010. Disponível em: < http://www.bn.br/portal/arquivos/pdf/Nielson_Bezerra.pdf >. Acesso em: 3 ago. 2014.

BRANDÃO, Ambrósio Fernandes. Diálogos das Grandezas do Brasil. Rio de Janeiro: Oficina Industrial Gráfica, 1930.

BRASIL. Constituição (1988). Constituição da República Federativa do Brasil. Belo Horizonte: Assembleia Legislativa do Estado de Minas Gerais, 2011.

BRASIL. Governo Federal. Lei n. ${ }^{\circ}$ 11. 645, de 10 de março de 2008. Que estabelece as diretrizes e bases da educação nacional, para incluir no currículo oficial da rede de ensino a obrigatoriedade da temática "Historia e Cultura Afro-Brasileira e indígena". Brasília, DF, 2008. Disponível em: < https://www. planalto.gov.br/ccivil_03/Leis/L9394.htm>. Acesso em: 10 maio 2010.

BRASIL. Presidência da República. Decreto $n^{\circ} 3.551$, de 4 de agosto de 2000. Brasília, DF, 2000. Disponível em: <http://www.cultura.gov.br/site/wp-content/uploads/2007/10/decreto3551.pdf>. Acesso em: 2 fev. 2011.

CAMINHA, Pero Vaz de. Carta ao rei D. Manuel I. São Paulo: Dominus, 1963 (A Biblioteca Virtual do Estudante Brasileiro). Disponível em: <http://www.bibvirt.futuro.usp. b $>$. Acesso em: 20 set. 2011.

CÉSAR, América Lúcia Silva. Lições de Abril: construção de autoria entre os Pataxó de Coroa Vermelha. 2002. Tese (Doutorado em Linguística Aplicada)-Instituto de Estudos da Linguagem da Universidade Estadual de Campinas, Campinas, 2002.

DESCOLA, Philippe. A selvageria culta. In: NOVAES, Adauto (Org.). A outra margem do Ocidente. São Paulo: Companhia das Letras, 1999. p. 107-123.

DESCOLA, Philippe. Estrutura ou sentimento: a relação com o animal na Amazônia. Manaus,, v.4, p. 23-45, 1998.

FOOD AND AGRICULTURE ORGANIZATION OF THE UNITED NATIONS (FAO). Faostat. 2013 a. Disponível em: < http://www.faostat.fao.org/ >. Acesso em: 26 ago. 2014.

FOOD AND AGRICULTURE ORGANIZATION OF THE UNITED NATIONS (FAO). Produzir mais com menos: Mandioca: um guia para a intensificação sustentável da produção. Rome, 2013 b. Disponível em: < http://www.fao.org/ag/save-and-Grow/cassava/pdf/FAOMandioca.pdf >. Acesso em: 26 ago. 2014.

GROSFOGUEL, R. Para descolonizar os estudos de economia política e os estudos póscoloniais: transmodernidade, pensamento de fronteira e colonialidade global. Revista Periferia, v.1, n.2, p. 115-147, 2008. 
GUIMARÃES, Francisco Alfredo Morais. A gente só conhece certo quando vê de perto: um novo olhar sobre a pesquisa entre os professores kiriri. Tese (Doutorado em Estudos Étnicos e Africanos)-Faculdade de Filosofia e Ciências Humanas da Universidade Federal da Bahia, Salvador, 2014.

IBGE - Instituto Brasileiro de Geografia e Estatística. Levantamento sistemático da produção agrícola. Rio de Janeiro: IBGE, v. 26, n. 3, p. 1-86, 23 maio 2013.

LITTLE, Paul E. Territórios sociais e povos tradicionais no Brasil: por uma antropologia da territorialidade. Brasília: Universidade de Brasília, 2002 (Série Antropologia).

MICELI, Paulo. Por outras histórias do Brasil. In: PINSKY, Jaime et al. O ensino de História e a criação do fato. 3. ed. São Paulo: Contexto, 1991. p. 31-42.

MUNARI, Lucia Chamlian. Memória Social e Ecologia Histórica: a agricultura de coivara das populações quilombolas do Vale do Ribeira e sua relação com a formação da Mata Atlântica. 2010. Dissertação (Mestrado em Ciências) — Instituto de Biociências-Universidade de São Paulo, São Paulo, 2010.

POSEY, Darrell A. Introdução: etnobiologia: teoria e prática. In: RIBEIRO, Berta (Coord..). Suma etnológica brasileira. Petrópolis: Vozes: FINEP, 1986 a. v.1: Etnobiologia, p. 15-25.

POSEY, Darrell A. Manejo da floresta secundária, capoeiras, campos e cerrados (KAYAPÓS). In: RIBEIRO, Berta (Coord.). Suma etnológica brasileira. Petrópolis: Vozes, 1986 b. v.1, p. 173-185.

PROFESSORES Pataxó de Barra Velha (Org.). Mãgute e Goyá Pataxó. Brasília, ANAÍ/MEC/CESE, 2007.

QUIJANO, Aníbal. Colonialidad del poder, eurocentrismo y América Latina. In: LANDER, Edgardo (Org.). La colonialidad del saber social: eurocentrismo y ciencias: perspectivas latino-americanas. Buenos Aires, Argentina: Ed. CLACSO, sept. 2005. p. 227-278 (Colección Sur Sur).

QUIJANO, Aníbal. Colonialidade do poder e classificação social. In: SANTOS, Boaventura de Sousa; MENESES, Maria Paula (Org.). Epistemologias do Sul. Coimbra: Liv. Almedina, 2009. p. 73-117.

QUIJANO, Aníbal. La colonialidad del poder y la experiencia cultural latinoamericana. In: BRICEÑO-LEÓN, Roberto; SONNTAG, Heinz R. (Org.). Pueblo, época y desarrollo: la sociología de América Latina. Caracas: Ed. Nueva Sociedad, 1998. p. 139-155.

ROBERT, Pascale de et al. A beleza das roças: agrobiodiversidade Mebêngôkre-Kayapó em tempos de globalização. Bol. Museu Paraense Emílio Goeldi: Ciências Humanas, Belém, v. 7, n. 2, p. 339-369, maio/ago. 2012

RUGENDAS, Johann Moritz. Casa de Farinha. 1835. Disponível em: < http://www.ermakoff.com.br/banco/thumbnails.php?album=159 >. Acesso em: 12 set. 2011.

SACRAMENTO, Valdinéa de Jesus. A dimensão transatlântica da mandioca: o caso dos mahi de Savalou, Benin. In: CONGRESSO LUSO-AFRO-BRASILEIRO DE CIÊNCIAS SOCIAIS, 11., 7-10 ago. 2011, Salvador, Bahia. Anais eletrônicos. Salvador: Universidade Federal da Bahia/Centro de Estudos Afro-Orientais, 2011. p. 1-10. 
Pontos de Interrogação, v. 4, n. 2, jul./dez. 2014

Revista do Programa de Pós-Graduação em Crítica Cultural

Universidade do Estado da Bahia (UNEB), Campus II — Alagoinhas — BA

SALGADO, Sebastião. Fotos do povo Zo'é. Disponível em: < http://www. funai.gov.br/index.php/comunicacao/galeria-de-imagens/2056-galeria-de-fotos-zo-e?start=1 >. Acesso em: 10 abr. 2014.

Santos, Boaventura de Sousa. A Universidade no século XXI: Para uma reforma democrática e emancipadora da Universidade. São Paulo: Cortez, 2004

Santos, Boaventura de Sousa. Para além do pensamento abissal: das linhas globais a uma ecologia dos saberes. Novos Estudos, São Paulo, CEBRAP, p. 71-94, 2007.

SANTOS, Boaventura de Sousa. Para uma revolução democrática da justiça. 2. ed. São Paulo: Cortez Editora, 2008.

SANTOS, Boaventura de Sousa (Org.). Semear outras soluções: os caminhos da biodiversidade e dos conhecimentos, 2009.

SISTEMA Agroflorestal Sucessional Biodiverso. Disponível em: < http:

//www.agrofloresta.net/educacao-agroflorestal/sistema-agroflorestal-sucessional-

biodiverso/>. Acesso em: 3 ago. 2010.

SOARES, Mariza de Carvalho. Engenho sim, de açúcar não: o engenho de farinha de Frans Post. Vária História, Belo Horizonte, v. 25, n. 41, p. 61-83, jan./jun. 2009.

SOARES Mariza de Carvalho. O vinho e a farinha, "zonas de sombra" na economia atlântica no século XVII. In: SOUSA, Fernando de (Coord.). A Companhia e as relações econômicas de Portugal com o Brasil, Inglaterra e a Rússia. Lisboa: CEPESE: Ed. Afrontamento, 2008. p. 215-232.

SOUSA, Gabriel Soares de. Tratado Descritivo do Brasil em 1587. 4.ed. Edição comentada por Francisco Adolfo de Varnhagen. São Paulo: Nacional, 1971.

THOMPSON, John B. Ideologia e cultura moderna: teoria social crítica na era dos meios de comunicação de massa. 6.ed. Rio de Janeiro: Vozes, 1990.

VIANNA, Letícia. Patrimônio Imaterial: legislação e inventários culturais: a experiência do Projeto Celebrações e Saberes da Cultura Popular. In: FONSECA, Maria Cecília Londres et al. Celebrações e saberes da cultura popular: pesquisa, inventário, crítica, perspectivas. Rio de Janeiro: CNFCP/Funarte/Iphan, 2004. p. 14-24 (Série Encontros e Estudos, v. 5).

VISTA Aérea de roça Suruí em aldeia da Terra Indígena Sete de Setembro. Disponível em: < http://www1.folha.uol.com.br/ambiente/2013/09/1340114-indios-de-ro-fecham-primeiravenda-de-carbono-certificado.shtml >. Acesso em: 10 abr. 2014.

VIVEIROS DE CASTRO, Eduardo B. Araweté: os deuses canibais. Rio de Janeiro: Jorge Zahar: ANPOCS, 1986.

WALLERSTEIN, Immanuel. The Capitalist World-Economy. Cambridge and Paris: Cambridge University Press: Editions de la Maison des Sciences de l'Homme, 1979.

WORLD FOODS - Cassava. Preparo de beiju na África. Disponível em: emhttp://thethirdcollection.wordpress.com/2013/05/29/world-foods-cassava/ Acesso em: out 2013

Recebido em: 19 de outubro de 2014.

Aceito em: 20 de novembro de 2014. 
